\title{
Speckle tracking echocardiography before and after Surgical pulmonary valve replacement in Tetralogy of Fallot patients: Can STE elucidate early left ventricular dysfunction?
}

Gholam Hossein Ajami

Shiraz University of Medical Sciences

Fathi Alwasabi

Shiraz University of Medical Sciences

Nima Mehdizadegan

Shiraz University of Medical Sciences

Mohammad Reza Edraki

Shiraz University of Medical Sciences

Hamid Mohammadi ( $\square$ mohammadi219@gmail.com)

Shiraz University of Medical Sciences https://orcid.org/0000-0002-6606-2795

Ahmad ali Amirghofran

Shiraz University of Medical Sciences

Bahram Ghasemzade

Shiraz University of Medical Sciences

Kambiz Keshavarz

Shiraz University of Medical Sciences

Hamid Amoozgar

Shiraz University of Medical Sciences

Hamid Arabi

Shiraz University of Medical Sciences

\section{Amir Naghshzan}

Shiraz University of Medical Sciences

Mohammad Borzouee

Shiraz University of Medical Sciences

Farah Peiravian

Shiraz University of Medical Sciences

Research 
Keywords: Speckle tracking echocardiography, surgical pulmonary valve replacement, Conventional 2D echocardiography, Interventricular interaction

Posted Date: January 2nd, 2020

DOl: https://doi.org/10.21203/rs.2.19898/v1

License: (c) (1) This work is licensed under a Creative Commons Attribution 4.0 International License. Read Full License 


\section{Abstract}

Objectives: TOF is the most common cyanotic CHD. We investigated left ventricular (LV) function after surgical pulmonary valve replacement (sPVR) in patients with repaired Tetralogy of Fallot (rTOF) by Speckle Tracking Echocardiography (STE).

Methods: 58 volunteers participated in this study who divided into 3 groups including 22 PVR patients (mean age $18.96 \pm 7$ year), 16 repaired Tetralogy of Fallot and 20 healthy age match control. For all patients, we performed 2D echocardiography and STE.

Results: 2D echocardiography in all groups showed normal LV ejection fraction without a significant statistical difference (64\% SPVR, $60 \%$ in repaired Tetralogy of Fallot and $62.5 \%$ in the control group). However, the mean global longitudinal strains (GLS) of LV were significantly reduced in both sPVR $(-17.5 \pm 2.5 \%)$ and repaired Tetralogy of Fallot $(-17.1 \pm 4.7 \%)$ patients rather than control group $(-20.2 \pm 0.7 \%)$ $(P=0.003)$. But GLS had no statistically significant difference between repaired Tetralogy of Fallot and sPVR patients $(P=0.9)$. Segmental analysis of longitudinal strain $(L S)$ showed a significant decrease in SPVR patients and repaired Tetralogy of Fallot group in basal anterior, basal septal, basal anterolateral segments, mid-anterior and anterolateral segments. Except for lower LS in the apical-anteroseptal segment, this level was mostly spared in both SPVR and repaired Tetralogy of Fallot patients.

Conclusion: LVEF was within normal range after SPVR patients, but the pattern of impaired segmental LS and GLS did not change as compared with rTOF. Surgical PVR in patients with repaired TOF may not have a significant effect on the improvement of LV function assessed by STE. LV damage which happens during surgical correction of TOF may have a permanent deteriorating effect on LV function.

\section{Introduction}

Tetralogy of Fallot is the most common form of congenital cyanotic heart disease, and despite the introduction of many surgical and interventional treatments, pulmonary regurgitation is the main cause of morbidity in long term management of these patients. It is well known that pulmonary regurgitation is progressive and may lead to right ventricle failure and then impaired left ventricle function(1-5). Pulmonary valve replacement (PVR) was suggested as an effective option to improve and ameliorate the volume overload resulting from pulmonary valve regurgitation $(2,6)$. Pulmonary valve replacement leads to improvement in functional class, exercise capacity, decreases QRS duration, interventricular interaction and quality of life and etc (7). As reported, the left ventricle dysfunction is a major determinant of clinical outcome in these patients, hence evaluation of left ventricle is important $(4,8-10)$. Although some studies have stated the importance of left ventricle function and size in repaired Tetralogy of Fallot patients, its usage as prognostic value is not adequate(4). In recent years, assessing myocardial motion strain by using Speckle tracking echocardiography is an emerging echocardiographic technique, increasingly used in heart disease diagnosis and management. Hence, it is useful for detecting subtle and early cardiac dysfunctions in several clinical conditions that cannot be discovered or diagnosed by conventional 2D 
echocardiography(11). In this study we focused on left ventricle parameters and the aim of this study was to identify patterns of systolic myocardial deformation in repaired Tetralogy of Fallot patients after surgical pulmonary valve replacement, using 2D speckle tracking echocardiography to assess left ventricle function and remodeling that might be undetectable by conventional $2 \mathrm{D}$ echocardiography.

\section{Material And Methods}

This study was approved by the local ethics committee of Shiraz University of Medical Sciences and written informed consent was obtained from all the participants or their guardian before recruitment. It was a single-center retrospective observational cross-sectional study that was performed off-line by a single observer. The assessment of ventricular function was done by left ventricular speckle tracking and conventional 2D transthoracic echocardiography with the Vivid S6 GE ultrasound machine. The study population included three groups: group 1, patients with repaired Tetralogy of Fallot after surgical pulmonary valve replacement, group 2, repaired Tetralogy of Fallot without pulmonary valve replacement and group 3 who were healthy individuals. We studied three groups including Tetralogy of Fallot with pulmonary valve replacement, repaired Tetralogy of Fallot and healthy volunteers who were matched in gender and age (Table 1). Inclusion criteria for repaired Tetralogy of Fallot group were: Age $>5$ years, any form of Tetralogy of Fallot or Tetralogy of Fallot -like (Double outlet right ventricle + severe pulmonary stenosis) lesion who had total surgical correction without homograft and acceptance to participate in this study. For the pulmonary valve replacement group, we included cases with Tetralogy of Fallot or Tetralogy of Fallot like lesion with mechanical or biological valve who had accepted to participate in this study. For the control group, healthy volunteers without a history of ischemic or congenital heart disease or major surgery were included.

Also, the following exclusion criteria were applied for all groups: any history of Kawasaki or coronary artery abnormality, history of uncontrolled tachyarrhythmia, significant residual shunt, inadequate imaging for off-line analysis, transposition of great arteries, and implanted pacemakers.

After ECG connection to each patient, two-dimensional grayscale harmonic images were obtained in the left lateral decubitus position with a probe S4-1 (3-7 MHz) at a frame rate of $60-90$ frames/s and appropriate frequency for the age. We used the guidelines of the American Society of Echocardiography for chamber measurements, including left ventricle ejection fraction (Teichholz formula), right ventricle fractional area change (FAC) (RV FAC (\%) = (RV EDA - RV ESA)/RV EDA x 100), Tricuspid annular plane systolic excursion (TAPSE). Longitudinal Speckle Tracking Echocardiography (STE) was done in 4 chambers, left ventricle two-chamber and long-axis views with semiautomatic AFI calculation method. After 3 points selection, the border of endocardial, myocardial and epicardial were adjusted by the user and then Echo machine started the automated process of Speckle tracking echocardiography. Data represented in 18 segments model. It should be mentioned, the apical segment usually not completely visualized and tracking in this area has many limitations. We took care and gathered multiple clips for each view to minimizing low-quality tracing. $(11,12)$ 
All statistical analysis was done using IBM SPSS V. 24. The data are described using mean \pm standard deviation $( \pm S D)$, median and ranges, when possible. Categorical variables were described using count and percentages. Box plot was drawn to show the upper and lower agreement between variables. The ANOVA test was used to compare different groups and a P-value less than 0.05 was considered to be statistically significant.

\section{Result}

From April 2015 to May 2017, 58 volunteers participated in this study; 22 patients with surgical pulmonary valve replacement after corrected Tetralogy of Fallot and 16 repaired Tetralogy of Fallot patients, and 20 healthy individuals as a control group. All were asymptomatic and underwent twodimensional and Speckle tracking echocardiography with a focus on the left ventricular function and right ventricular dimension and function. Demography and characters of all three groups are shown in Table 1. Among the pulmonary valve replacement group, there were 12(55\%) male and 10 (45\%) females. Surgical pulmonary valve replacement was performed at mean age of $14.8 \pm 6.6$ years (range from 6 to 29 years) and total correction of Tetralogy of Fallot at $3.2 \pm 1.3$ years. In the PVR group, 14 were on medication such as antiplatelet and anti-coagulation but in the rTOF group, only 3 patients were on medication including digoxin, captopril and furosemide. In the surgical pulmonary valve replacement group, 16 cases $(72.7 \%)$ had a bioprosthetic valve, $6(27.3 \%)$ had a mechanical valve. In pulmonary valve replacement group,12 (55\%) had one operation prior to surgical pulmonary valve replacement (total correction of Tetralogy of Fallot) and $8(36 \%)$ had 2 operations (modified Blalock Taussig shunt + total correction of Tetralogy of Fallot) and remaining 2(9\%)had more than two operations. 
Table 1

Demographic features of all groups.

\begin{tabular}{|c|c|c|c|c|}
\hline $\begin{array}{l}\text { Baseline and demographic } \\
\text { characteristics }\end{array}$ & rTOF + sPVR & rTOF & Normal & $\begin{array}{l}P \\
\text { value }\end{array}$ \\
\hline Number (\%) & 22 & 16 & 20 & \\
\hline Male/Female, n (\%) & $12 / 10(55 \% / 45 \%)$ & $8 / 8(50 \% / 50 \%)$ & $12 / 8(60 \% / 40 \%)$ & 0.8 \\
\hline Age at time study (year) (rang) & $18.9 \pm 7(15-31)$ & $\begin{array}{l}20.6 \pm 7.4 \\
(16-25)\end{array}$ & $\begin{array}{l}19.1 \pm 7.8(16- \\
27)\end{array}$ & 0.76 \\
\hline Age at operation (rang) & $14.8 \pm 6.6(6-29)$ & $\begin{array}{l}3.2 \pm 1.3(1.5- \\
5)\end{array}$ & & \\
\hline $\begin{array}{l}\text { Studied after PVR and repaired } \\
\text { TOF(year) }\end{array}$ & $4.2 \pm 3$ & $17.4 \pm 8$ & & \\
\hline \multicolumn{5}{|l|}{ Diagnosis } \\
\hline TOF preserved valve & $6(25 \%)$ & $4(25 \%)$ & & \\
\hline TOF-TAP & $12(55 \%)$ & $9(56 \%)$ & & \\
\hline TOF-Absent LPA & $1(5 \%)$ & & & \\
\hline $\begin{array}{l}\text { DORV-VSD-PS-AP window-severe } \\
\text { Al-dilated aortic root and AAO }\end{array}$ & $1(5 \%)$ & & & \\
\hline DORV-VSD-PS- TAP & $1(5 \%)$ & $3(19 \%)$ & & \\
\hline TOF-absent pulmonary valve syn. & $1(5 \%)$ & & & \\
\hline $\begin{array}{l}\text { Number of prior surgery before } \\
\text { PVR } \\
\text { One surgery } \\
2 \text { and more }\end{array}$ & \multicolumn{3}{|c|}{$\begin{array}{l}\text { One surgery } \\
2 \text { and more }\end{array}$} & \\
\hline Weight & $52.2 \pm 18$ & $46 \pm 13.3$ & $51.8 \pm 17.8$ & 0.5 \\
\hline $\begin{array}{l}\text { Type of prosthetic valve, } \mathrm{n}(\%) \\
\text { - Biologic } \\
\text { - Mechanical }\end{array}$ & $\begin{array}{l}16(72.7 \%) \\
6(27.3 \%)\end{array}$ & & & \\
\hline $\begin{array}{l}\text { DORV, double outlet right ventricle; } \\
\text { ventricular septum; PA, pulmonary } \\
\text { pulmonary valve; RVOT, right ventric } \\
\text { patch. }\end{array}$ & $\begin{array}{l}\text { GA, d-loop transpo } \\
\text { esia; PR, pulmonary } \\
\text { ar outflow tract; TO }\end{array}$ & $\begin{array}{l}\text { ition of the great } \\
\text { regurgitation; PS, } \\
\text {; tetralogy of Fall }\end{array}$ & $\begin{array}{l}\text { rteries; IVS, intact } \\
\text { ulmonary stenosis } \\
\text { t; TAP: Transannul }\end{array}$ & PV, \\
\hline
\end{tabular}

Standard echocardiographic parameters are shown in Table 2. The presence of pulmonary regurgitation and right ventricular outflow tract gradient were assessed by color Doppler and continuous wave Doppler. It revealed moderate or greater pulmonary regurgitation in all repaired Tetralogy of Fallot but only mild pulmonary valve regurgitation in the surgical pulmonary valve replacement group. Pulmonary valve 
replacement group had a higher right ventricular outflow tract peak gradient (RVOT PG) rather than repaired Tetralogy of Fallot $(18.6 \pm 12 \mathrm{mmHg}$ vs $12.7 \pm 8 \mathrm{mmHg}$; P-value $=0.02)$ but both groups had no significant residual stenosis regard of surgical or interventional approach. The right ventricle dimensions was significantly lower in the surgical PVR group rather than repaired Tetralogy of Fallot as shown in Fig. 1 and Table 2. Both TAPSE and FAC\% after surgical pulmonary valve replacement were significantly higher as compared with repaired Tetralogy of Fallot (Table 2 ).

Although there was a significant difference in right ventricle 2D echocardiographic parameters, the left ventricle 2D echocardiographic parameter didn't show significant abnormality in either repaired TOF or pulmonary valve replacement groups (Table 2). Interestingly, 2D echocardiography reports normal ejection fraction (EF > 55\%) in both repaired Tetralogy of Fallot and pulmonary valve replacement group.

Table 2

2D echocardiographic parameters in the PVR and rTOF patients

\begin{tabular}{|llll|}
\hline Characteristic & sPVR & rTOF & P value \\
\hline LV EF (\%) & $64.5 \pm 6.5$ & $60 \pm 10.2$ & 0.1 \\
\hline RVOT PG & $18.6 \pm 12$ & $12.7 \pm 8$ & $0.02^{\star}$ \\
\hline RV FAC (\%) & $44 \pm 7.2$ & $35.3 \pm 8.9$ & 0.002 \\
\hline TAPSE (mm) & $15.3 \pm 2.7$ & $12.2 \pm 2.5$ & $<0.001$ \\
\hline $\begin{array}{l}\text { RV end-systolic dimension } \\
\text { (A4C view) (mm) }\end{array}$ & $14.4 \pm 3.2$ & $26 \pm 4.6$ & $<0.001$ \\
\hline $\begin{array}{l}\text { RV end-diastolic dimension } \\
\text { (A4C view) (mm) }\end{array}$ & $26.2 \pm 6$ & $40.4 \pm 4$ & $<0.001$ \\
\hline $\begin{array}{l}\text { EDD end-diastolic dimension, EF ejection fraction, FAC RV fractional area change (\%), RV right } \\
\text { ventricular, RVOT PG right ventricular outflow tract pressure gradient, TAPSE tricuspid annular planar } \\
\text { systolic excursion, TDI tissue Doppler imaging. Data are expressed as mean } \pm \text { SD. }\end{array}$ & \\
\hline
\end{tabular}

Mean global longitudinal systolic strain of left ventricle was significantly lower in both PVR $(-17.5 \pm 2.5)$ and repaired TOF $(-17.1 \pm 4.7)$ compared to normal $(-20.2 \pm 0.7)$ group with p-value $<0.003$. (Table 3$)$ The segmental analysis also showed a significant statistical difference in most segments between the normal group and those of repaired TOF and surgical PVR patients; All basal segments had a lower longitudinal strain (LS), except in basal inferior and inferolateral segments (Table 3). The apical level is the most spared area. In mid-level, both anterior and anterolateral segments had a lower longitudinal strain (Table 3). Pulmonary valve replacement did not change the segmental strain pattern and we did not observe any improvement in the global or segmental longitudinal strain compare with the repaired TOF group. 
Table 3

The peak systolic longitudinal strain of the LV walls in SPVR, rTOF patients and the healthy controls (Pvalue $<0.05$ indicate significance the difference between groups)

\begin{tabular}{|c|c|c|c|c|c|c|}
\hline & Segments & $\begin{array}{l}\text { sPVR } \\
N=22\end{array}$ & $\begin{array}{l}\text { rTOF } \\
n=16\end{array}$ & $\begin{array}{l}\text { PVR vs. } \\
\text { rTOF } \\
\text { P-value }\end{array}$ & $\begin{array}{l}\text { Normal } \\
\mathrm{N}=20\end{array}$ & $\begin{array}{l}\text { PVR or rTOF vs } \\
\text { normal control } \\
\text { P-value } \\
\text { (significance are } \\
\text { bold) }\end{array}$ \\
\hline & $\begin{array}{l}\text { Global Longitudinal LV } \\
\text { Strain (\%) }\end{array}$ & $\begin{array}{l}-17.5 \pm \\
2.5\end{array}$ & $\begin{array}{l}-17.1 \pm \\
4.7\end{array}$ & 0.9 & $\begin{array}{l}-20.2 \pm \\
0.7\end{array}$ & $0.003^{*}$ \\
\hline \multirow[t]{6}{*}{ Basal } & Anterior & $\begin{array}{l}-14.04 \\
\pm 5.7\end{array}$ & $\begin{array}{l}-14.88 \\
\pm 4\end{array}$ & 0.61 & $\begin{array}{l}-19.7 \pm \\
1.9\end{array}$ & $<0.001$ \\
\hline & Anteroseptal & $\begin{array}{l}-15.63 \\
\pm 3.8\end{array}$ & $\begin{array}{l}-15.81 \\
\pm 5.4\end{array}$ & 0.89 & $\begin{array}{l}-18.85 \\
\pm 2.8\end{array}$ & 0.021 \\
\hline & Inferoseptal & $\begin{array}{l}-17.13 \\
\pm 5.6\end{array}$ & $\begin{array}{l}-18.56 \\
\pm 4.7\end{array}$ & 0.4 & $\begin{array}{l}-20.9 \pm \\
2.5\end{array}$ & 0.028 \\
\hline & Inferior & $\begin{array}{l}-18.46 \\
\pm 4.3\end{array}$ & $\begin{array}{l}-18.19 \\
\pm 5.5\end{array}$ & 0.86 & $\begin{array}{l}-21 \pm \\
2.2\end{array}$ & 0.071 \\
\hline & Anterolateral & $\begin{array}{l}-14.92 \\
\pm 5.8\end{array}$ & $\begin{array}{l}-15.06 \\
\pm 4.7\end{array}$ & 0.93 & $\begin{array}{l}-19.5 \pm \\
2.8\end{array}$ & 0.004 \\
\hline & Inferolateral & $\begin{array}{l}-18.04 \\
\pm 5.3\end{array}$ & $\begin{array}{l}-15.94 \\
\pm 5.9\end{array}$ & 0.27 & $\begin{array}{l}-19.15 \\
\pm 3.7\end{array}$ & 0.165 \\
\hline \multirow[t]{6}{*}{ Middle } & Anterior & $\begin{array}{l}-15.5 \pm \\
4.1\end{array}$ & $\begin{array}{l}-15.25 \\
\pm 4.1\end{array}$ & 0.85 & $\begin{array}{l}-20.2 \pm \\
1.8\end{array}$ & $<0.001$ \\
\hline & Anteroseptal & $\begin{array}{l}-17.92 \\
\pm 4.6\end{array}$ & $\begin{array}{l}-17.25 \\
\pm 5.8\end{array}$ & 0.68 & $\begin{array}{l}-19.7 \pm \\
2\end{array}$ & 0.211 \\
\hline & Inferoseptal & $\begin{array}{l}-19.42 \\
\pm 5.2\end{array}$ & $\begin{array}{l}-19.63 \\
\pm 5.8\end{array}$ & 0.9 & $\begin{array}{l}-22.2 \pm \\
3.1\end{array}$ & 0.126 \\
\hline & Inferior & $\begin{array}{l}-19.25 \\
\pm 3.4\end{array}$ & $\begin{array}{l}-18.69 \\
\pm 5.7\end{array}$ & 0.69 & $\begin{array}{l}-21.1 \pm \\
1.5\end{array}$ & 0.123 \\
\hline & Anterolateral & $\begin{array}{l}-16.33 \\
\pm 3.8\end{array}$ & $\begin{array}{l}-16.38 \\
\pm 4.9\end{array}$ & 0.97 & $\begin{array}{l}-19.3 \pm \\
2.6\end{array}$ & 0.024 \\
\hline & Inferolateral & $\begin{array}{l}-17.58 \\
\pm 4.4\end{array}$ & $\begin{array}{l}-17.69 \\
\pm 5.6\end{array}$ & 0.94 & $\begin{array}{l}-20 \pm \\
3.8\end{array}$ & 0.175 \\
\hline \multirow[t]{2}{*}{ Apical } & Anterior & $\begin{array}{l}-17.83 \\
\pm 4.6\end{array}$ & $\begin{array}{l}-16.56 \\
\pm 6.1\end{array}$ & 0.45 & $\begin{array}{l}-19.6 \pm \\
2.2\end{array}$ & 0.128 \\
\hline & Anteroseptal & $\begin{array}{l}-16.4 \pm \\
3.5\end{array}$ & $\begin{array}{l}-16.4 \pm \\
3.9\end{array}$ & 0.98 & $\begin{array}{l}-20.4 \pm \\
2.8\end{array}$ & $<0.001$ \\
\hline
\end{tabular}




\begin{tabular}{|c|c|c|c|c|c|}
\hline Segments & $\begin{array}{l}\text { sPVR } \\
N=22\end{array}$ & $\begin{array}{l}\text { rTOF } \\
n=16\end{array}$ & $\begin{array}{l}\text { PVR vs. } \\
\text { rTOF } \\
\text { P-value }\end{array}$ & $\begin{array}{l}\text { Normal } \\
\mathrm{N}=20\end{array}$ & $\begin{array}{l}\text { PVR or rTOF vs } \\
\text { normal control } \\
\text { P-value } \\
\text { (significance are } \\
\text { bold) }\end{array}$ \\
\hline Inferoseptal & $\begin{array}{l}-20.2 \pm \\
3.8\end{array}$ & $\begin{array}{l}-18.4 \pm \\
4.5\end{array}$ & 0.2 & $\begin{array}{l}-20.9 \pm \\
3.9\end{array}$ & 0.17 \\
\hline Inferior & $\begin{array}{l}-19.92 \\
\pm 4.3\end{array}$ & $\begin{array}{l}-18.75 \\
\pm 6.1\end{array}$ & 0.45 & $\begin{array}{l}-20.45 \\
\pm 2\end{array}$ & 0.497 \\
\hline Anterolateral & $\begin{array}{l}-18.75 \\
\pm 3.3\end{array}$ & $\begin{array}{l}-16.7 \pm \\
3\end{array}$ & 0.053 & $\begin{array}{l}-18.7 \pm \\
2.4\end{array}$ & 0.7 \\
\hline Inferolateral & $\begin{array}{l}-16.83 \\
\pm 3.5\end{array}$ & $\begin{array}{l}-17.06 \\
\pm 4.3\end{array}$ & 0.85 & $\begin{array}{l}-19.15 \\
\pm 2.9\end{array}$ & 0.78 \\
\hline
\end{tabular}

\section{Discussion}

To best of our knowledge, this is one of the few studies that has focused on the left ventricle function by using 2D speckle tracking echocardiography in repaired Tetralogy of Fallot patients after surgical pulmonary valve replacement. This study revealed that moderate to severe pulmonary regurgitation seen in rTOF, eliminated in the surgical pulmonary valve replacement group. As it is expected, after eliminating right ventricle volume overload with surgical pulmonary valve replacement, the impaired right ventricle function returns to normal or near normal. We showed significant difference in right ventricle FAC after surgical pulmonary valve replacement similar to Hasan et al.(13). This parameter is dependent on the time of surgery, right ventricle condition before surgical PVR and surgical technique and its complications. It expects that deterioration of right ventricle parameters in repaired TOF would improve with surgical PVR. This improvement may affect left ventricle parameters by interventricular interaction. While the left ventricle ejection fraction was within normal range with no significant changes after surgical pulmonary valve replacement similar to other studies $(3,14-17), 2 \mathrm{D}$ speckle tracking showed reduced (deterioration) global longitudinal peak systolic strains in both pulmonary valve replacement and repaired Tetralogy of Fallot patients. Such finding reveals the limitation of routine 2D echocardiography to assess and follow up of left ventricle function in these groups of patients. Speckle tracking echocardiography is more sensitive to the detection of left ventricle abnormalities than $2 \mathrm{D}$ echocardiography $(3,15,18-23)$, and with regarding our finding it may be useful to unmask left ventricle dysfunction in the setting of repaired Tetralogy of Fallot follow up. Although to evaluate this hypothesis, we suppose more studies and prospective analysis of Speckle tracking echocardiography role in repaired Tetralogy of Fallot patients.

Another point in our study related to a non-significant change of left ventricular speckle tracking echocardiography in surgical PVR patients versus repaired TOF at both global and segmental longitudinal strains. Moiduddin et al., Myrthe E. Menting et al., and Burkhardt B. et al. with different study 
setting (Interventional pulmonary valve replacement and short term 6 month follow up) are in agreement with us $(14,17,20)$. However, such findings are not in agreement with the report of Chowdhury et al who reported improvement in left ventricle strain after transcutaneous pulmonary valve replacement. (15) It seems the current criteria for pulmonary valve replacement with regard of these finding and with respect to controversies in the field, may has little benefit for left ventricular function when assessed by speckle tracking echocardiography. Now the question is when left ventricle dysfunction in Speckle tracking echocardiography of repaired Tetralogy of Fallot has happened? Whether permanent damages to left ventricle had been happened at the time of repaired Tetralogy of Fallot surgery or the damage gradually has been developed after repaired Tetralogy of Fallot as a complication of pulmonary valve regurgitation and delayed pulmonary valve replacement (related to the current pulmonary valve replacement criteria). The conflict of data between different studies in improvement of speckle tracking echocardiography may indicate a non-permanent nature of theses damages and so the second hypothesis is more likely (that left ventricle dysfunction gradually develops during the time passed for surgical pulmonary valve replacement). To clarifying the role of speckle tracking echocardiography in the decision for the time of surgical pulmonary valve replacement, a prospective study with focusing on speckle tracking echocardiography after repaired Tetralogy of Fallot proposed. Meanwhile we may suggest that if any left ventricle dysfunction detected by Speckle tracking echocardiography after surgical pulmonary valve replacement, we should consider secondary problems such as coronary abnormalities which may need further evaluation by other modalities.

\section{Limitation:}

First, due to the limited number of study population more researches are recommended with a larger population. Secondly, preoperative Speckle tracking echocardiography data were not available in surgical pulmonary valve replacement patients, so the data were compared with repaired Tetralogy of Fallot as the control group. Finally, using only one probe to obtain standard images was another limitation. A different group of repaired TOF and PVR instead of longitudinal follows up of one group of repaired Tetralogy of Fallot is another limitation of this study.

\section{Conclusions}

Speckle tracking echocardiography versus 2D echocardiography is a more sensitive method to detect left ventricular abnormality in repaired Tetralogy of Fallot and surgical pulmonary valve replacement, particularly for segmental abnormalities. In addition, it is worthy to mention that there was no significant difference in GLS of surgical PVR and repaired TOF patients. The most involved areas in surgical pulmonary valve replacement with deteriorated longitudinal strain were apical anteroseptal, middle anterior and anterolateral segments, and basal septal, anterior and anterolateral segments.

We may recommend intermittent speckle tracking echocardiography during follow up of repaired TOF and surgical PVR patients to detect any deterioration of left ventricular function, especially when 2D echocardiography is not consistent with the sign and symptom of patients. 


\section{Declarations}

Ethics approval and consent to participate: All procedures performed in this study were in accordance with the ethical standards of the "Research Ethics Committee of Shiraz University of Medical Sciences" and with the 1964 Helsinki declaration and its later amendments or comparable ethical standards. This study was submitted to and approved by the "Research Ethics Committee of Shiraz University of Medical Sciences" with Ethics code IR.SUMS.REC.1395.S633.

Consent for publication: This manuscript does not contain any personal data, and the consent for publication is applicable.

Ethical approval and consent to participate: The study was explained for the patients or guardians and informed consent forms were signed by them.

Availability of Data and Materials: We state that the data used and/or analyzed during the current study are available from the corresponding author on reasonable request. Data sharing is applicable to this article and datasets were generated and analyzed during the current study and data sharing is allowed.

\section{Funding:}

This article was funded by Shiraz University of Medical Sciences. All of the Echocardiographic evaluations were performed in this university. The funder had no impact on study design, analysis, or result interpretation.

\section{Acknowledgment:}

We would like to thank doctor Z. Kheirandish and Moarref for their support and suggestions. We acknowledge Miss F. Beladi for her helpful collaboration in data collection. The authors would like to thank the Shiraz University of Medical Sciences, Shiraz, Iran, and also Center for Development of Clinical Research of Nemazee Hospital and Mr. H.Argasi at the Research Consultation Center for his invaluable assistance in editing this manuscript.

\section{Author contributions:}

GhA: design and analysis and manuscript preparation

FA: Sample collection and data preparation, manuscript preparation

HM : Design, analysis, statistics and manuscript preparation

M.R.E: Data collection and Drafting, analysis

AAA: patient referring, data collection and Drafting

NM: critical revision and manuscript preparation 
HA: drafting

MB: critical revision

KK: sample collection and data preparation

FP: critical revision, patient referring

AN: critical revision, patient referring

BG: patient referring, data collection and Drafting

All authors read and approved the final manuscript

Competing interest:

The authors declare that they have no competing interests.

\section{Abbreviations}

2D/2DE Two dimensional +/- echocardiography

GLS Global longitudinal strains

FAC Fractional area change

MAPSE Mitral annular plane systolic excursion

LV Left ventricle

RV Right ventricle

rTOF repaired Tetralogy of Fallot

PVR pulmonary valve replacement

PR/PI Pulmonary valve regurgitation/Pulmonary valve insufficiency

TDI Tissue Doppler interrogation

STE Speckle tracking echocardiography

TAPSE Tricuspid annular plane systolic excursion

RVOT Right ventricular outflow tract peak gradient

PG Peak gradient 


\section{References}

1. Quail MA, Frigiola A, Giardini A, Muthurangu V, Hughes M, Lurz P, et al. Impact of pulmonary valve replacement in tetralogy of Fallot with pulmonary regurgitation: a comparison of intervention and nonintervention. The Annals of thoracic surgery. 2012;94(5):1619-26.

2. Holmes KW. Timing of pulmonary valve replacement in tetralogy of Fallot using cardiac magnetic resonance imaging. Journal of the American College of Cardiology; 2012.

3. Dragulescu A, Friedberg MK, Grosse-Wortmann L, Redington A, Mertens L. Effect of chronic right ventricular volume overload on ventricular interaction in patients after tetralogy of Fallot repair. Journal of the American Society of Echocardiography. 2014;27(8):896-902.

4. Kempny A, Diller G-P, Orwat S, Kaleschke G, Kerckhoff G, Bunck AC, et al. Right ventricular-left ventricular interaction in adults with tetralogy of Fallot: a combined cardiac magnetic resonance and echocardiographic speckle tracking study. International journal of cardiology. 2012;154(3):259-64.

5. Allen HD. Moss \& Adams' Heart Disease in Infants, Children, and Adolescents, Including the Fetus and Young Adult. Wolters Kluwer Health; 2016.

6. Bigdelian H, Sedighi M, Mardani D. Right ventricular Hemodynamic Alteration after Pulmonary Valve Replacement in Children with Congenital Heart Disease. Journal of Cardio-Thoracic Medicine. 2015;3(1):273-7.

7. Lee C, Kim YM, Lee C-H, Kwak JG, Park CS, Song JY, et al. Outcomes of pulmonary valve replacement in 170 patients with chronic pulmonary regurgitation after relief of right ventricular outflow tract obstruction: implications for optimal timing of pulmonary valve replacement. Journal of the American College of Cardiology. 2012;60(11):1005-14.

8. Menting ME, Eindhoven JA, van den Bosch AE, Cuypers JA, Ruys TP, van Dalen BM, et al. Abnormal left ventricular rotation and twist in adult patients with corrected tetralogy of Fallot. European Heart Journal-Cardiovascular Imaging. 2014;15(5):566-74.

9. Menting ME, van den Bosch AE, McGhie JS, Eindhoven JA, Cuypers JA, Witsenburg M, et al. Assessment of ventricular function in adults with repaired Tetralogy of Fallot using myocardial deformation imaging. Eur Heart J Cardiovasc Imaging. 2015:jev090.

10. Takayasu H, Takahashi K, Takigiku K, Yasukochi S, Furukawa T, Akimoto K, et al. Left ventricular torsion and strain in patients with repaired tetralogy of Fallot assessed by speckle tracking imaging. Echocardiography. 2011;28(7):720-9.

11. Forsey J, Friedberg MK, Mertens L. Speckle tracking echocardiography in pediatric and congenital heart disease. Echocardiography. 2013;30(4):447-59. doi:10.1111/echo.12131. [PubMed:23551605].

12. Ajami G, Edraki MR, Moarref AR, Amirghofran AA, Borzouee M, Amoozgar H, et al. Role of speckle tracking echocardiography in the assessment of post-repair left ventricular function in patients with late presentation of anomalous origin of the left coronary artery from the pulmonary artery. Cardiol Young. 2015;25(5):969-75. doi:10.1017/s1047951114001486. [PubMed:25155805]. 
13. Hasan BS, Lunze FI, Chen MH, Brown DW, Boudreau MJ, Rhodes J, et al. Effects of transcatheter pulmonary valve replacement on the hemodynamic and ventricular response to exercise in patients with obstructed right ventricle-to-pulmonary artery conduits. JACC: Cardiovascular Interventions. $2014 ; 7(5): 530-42$.

14. Moiduddin N, Asoh K, Slorach C, Benson LN, Friedberg MK. Effect of transcatheter pulmonary valve implantation on short-term right ventricular function as determined by two-dimensional speckle tracking strain and strain rate imaging. The American journal of cardiology. 2009;104(6):862-7.

15. Chowdhury SM, Hijazi ZM, Rhodes JF, Kar S, Makkar R, Mullen M, et al. Changes in speckle tracking echocardiography measures of ventricular function after percutaneous implantation of the Edwards SAPIEN transcatheter heart valve in the pulmonary position. Echocardiography. 2015;32(3):461-9.

16. Kutty S, Deatsman SL, Russell D, Nugent ML, Simpson PM, Frommelt PC. Pulmonary valve replacement improves but does not normalize right ventricular mechanics in repaired congenital heart disease: a comparative assessment using velocity vector imaging. Journal of the American Society of Echocardiography. 2008;21(11):1216-21.

17. Burkhardt BE, Forte MNV, Durairaj S, Rafiq I, Valverde I, Tandon A, et al. Timely Pulmonary Valve Replacement May Allow Preservation of Left Ventricular Circumferential Strain in Patients with Tetralogy of Fallot. Frontiers in Pediatrics. 2017;5.

18. Fernandes FP, Manlhiot C, Roche SL, Grosse-Wortmann L, Slorach C, McCrindle BW, et al. Impaired left ventricular myocardial mechanics and their relation to pulmonary regurgitation, right ventricular enlargement and exercise capacity in asymptomatic children after repair of tetralogy of Fallot. Journal of the American Society of Echocardiography. 2012;25(5):494-503.

19. Li Y, Xie M, Wang X, Lv Q, Lu X, Yang Y, et al. Evaluation of right ventricular global longitudinal function in patients with tetralogy of fallot by two-dimensional ultrasound speckle tracking imaging. Journal of Huazhong University of Science and Technology-Medical Sciences-. 2010;30(1):126-31.

20. Li S-n, Yu W, Lai CT-m, Wong SJ, Cheung Y-f. Left ventricular mechanics in repaired tetralogy of Fallot with and without pulmonary valve replacement: analysis by three-dimensional speckle tracking echocardiography. PloS one. 2013;8(11):e78826.

21. Yamada M, Takahashi K, Kobayashi M, Yazaki K, Takayasu H, Akimoto K, et al. Mechanisms of Left Ventricular Dysfunction Assessed by Layer-Specific Strain Analysis in Patients With Repaired Tetralogy of Fallot. Circulation Journal. 2017;81(6):846-54.

22. Li Y, Xie M, Wang X, Lu Q, Zhang L, Ren P. Impaired Right and Left Ventricular Function in Asymptomatic Children with Repaired Tetralogy of Fallot by Two-Dimensional Speckle Tracking Echocardiography Study. Echocardiography. 2015;32(1):135-43.

23. Mohammad Nijres B, Bokowski J, Al-Kubaisi M, Abdulla R-i, Murphy JJ, Awad S, et al. Use of Speckle Tracking Echocardiography to Assess Left Ventricular Systolic Function in Patients with Surgically Repaired Tetralogy of Fallot: Global and Segmental Assessment. Pediatric Cardiology. 2018;39(8):1669-75. doi:10.1007/s00246-018-1950-4. 


\section{Figures}
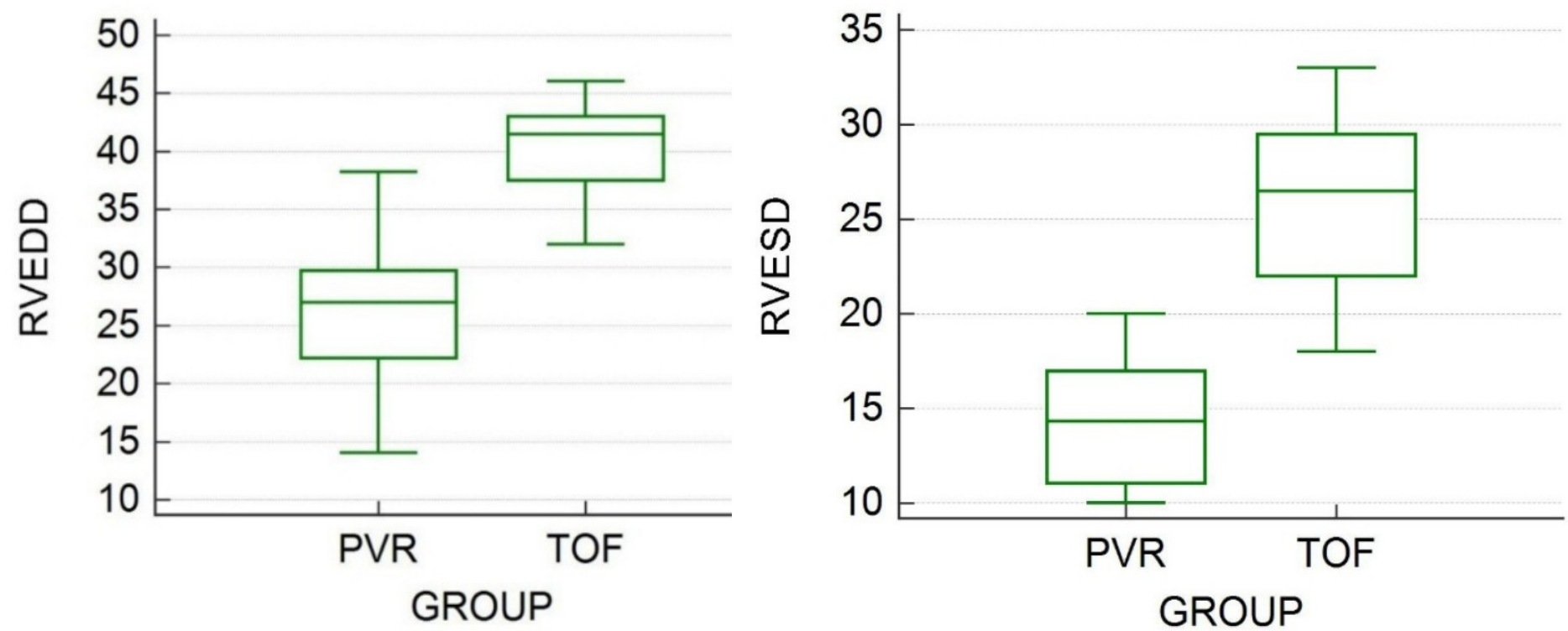

Figure 1

Box plot showing right ventricle end-diastolic $(\mathrm{mm})$ and right ventricle end-systolic dimensions $(\mathrm{mm})$ in pulmonary valve replacement and repaired Tetralogy of Fallot groups
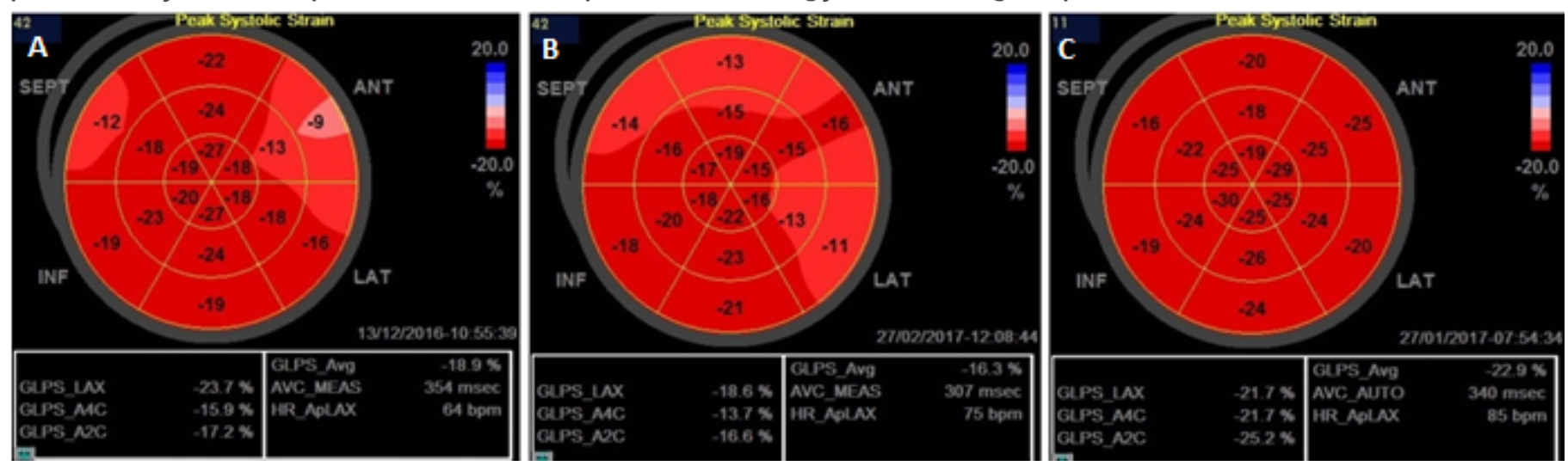

Figure 2

The bullseye schematic and global strain in a sPVR, repaired Tetralogy of Fallot and a normal case from left to right, respectively 